\title{
Cytokine Control of Parasite-specific Anergy in Human Lymphatic Filariasis Preferential Induction of a Regulatory T Helper Type 2 Lymphocyte Subset
}

\author{
Christopher L. King, ${ }^{*}$ Siddhartha Mahanty, * V. Kumaraswami, ${ }^{5}$ John S. Abrams, " Jaya Regunathan," \\ Kunthala Jayaraman," Eric A. Ottesen, * and Thomas B. Nutman * \\ * Laboratory of Parasitic Diseases, National Institutes of Health, Bethesda, Maryland 20892; ${ }^{\ddagger}$ Division of Geographic Medicine, \\ Case Western Reserve University, Cleveland, Ohio 44106; ${ }^{\S}$ Tuberculosis Research Center; and "Department of Biotechnology, \\ Anna University, Madras 600025, India; and $₫$ DNAX Research Institute, Palo Alto, California 94304
}

\begin{abstract}
The immunological mechanisms involved in maintenance of an asymptomatic microfilaremic state (MF) in patients with lymphatic filariasis remain undefined. MF patients have impaired filarial antigen ( $\mathrm{Ag}$ )-specific lymphocyte proliferation and decreased frequencies ( $\mathrm{Fo}$ ) of $\mathrm{Ag}$-specific $\mathrm{T}$ cells, and yet elevated serum IgE and antifilarial IgG4. To investigate the mechanism of Ag-specific anergy in MF patients in contrast to amicrofilaremic individuals with chronic lymphatic obstruction (CP), the Fo of Ag-specific lymphocytes from peripheral blood mononuclear cells secreting either IL-4 or IFN- $\gamma$ were assessed by filter spot enzyme-linked immunosorbent assay, and IL-10 and transforming growth factor $-\beta$ (TGF- $\beta$ ) mRNA transcript levels were assessed by a semiquantitative reverse transcriptase polymerase chain reaction technique. The Fo of filariaspecific IL-4-secreting lymphocytes were equivalent in both MF (geometric mean $[G M]=1: 11,700)$ and $C P(G M$ $=1: 29,300 P=0.08$ ), whereas the Fo of IFN- $\gamma$-secreting lymphocytes were lower in MF (GM $=1: 39,300)$ than in CP (GM $=1: 4,200, P<0.01)$. When the ratio of IL-4/IFN- $\gamma(T$ helper type $2[$ Th2]/Th1 )-secreting cells was examined, MF subjects showed a predominant $T h 2$ response (8:1) compared with a Th1 response in CP individuals (1:4). mRNA transcript levels of IL-10 were also significantly elevated in MF compared with CP individuals $(P<0.01)$. Further, IL-10 and TGF- $\beta$ were shown to have a role in modulating the Ag-specific anergy among MF subjects, in that neutralizing anti-IL-10 or antiTGF- $\beta$ significantly enhanced lymphocyte proliferation response (by 220-1,300\%) to filarial Ags in MF individuals. These findings demonstrate that MF subjects respond to parasite antigen by producing a set of suppressive cytokines that may facilitate persistence of the parasite within humans while producing little clinical disease. (J. Clin. Invest. 1993. 92:1667-1673.) Key words: lymphatic filariasis • tolerance $\bullet T$ helper subsets • IL-10 • ELISPOT
\end{abstract}

\section{Introduction}

The human lymphatic filariases, estimated to affect $\sim 100$ million people worldwide, produce a range of host immune responses that have been implicated in the pathogenesis of the different clinical manifestations of this infection (1). Host reac-

Address correspondence to Dr. Christopher L. King, Division of Geographic Medicine, Case Western Reserve University School of Medicine, 2109 Adelbert Road, Cleveland, OH 44106-4983

Received for publication 30 November 1992 and in revised form 11 May 1993.

The Journal of Clinical Investigation, Inc.

Volume 92, October 1993, 1667-1673 tions to both brugian and bancroftian filariasis infections range from those of asymptomatic individuals with circulating microfilariae to others who exhibit chronic lymphedema and occasionally pulmonary symptoms ( tropical pulmonary eosinophilia) but have no circulating microfilariae (2). This breadth of host reaction to infection may reflect the nature of different individuals' immune response to filarial infection $(2,3)$. For example, asymptomatic microfilaremia (MF) ${ }^{1}$ is thought to result from parasite-specific "immune hyporesponsiveness" by the host, thereby allowing the microfilariae to persist in the circulation (3-5). This hypothesis has been supported by observations of selectively impaired $T$ and $B$ cell responses to filarial antigens (Ags) among MF subjects (3-11), but the Agspecific anergy does not extend to all immune responses in MF individuals, as frequencies of polyclonal IgE- and IgG4-secreting lymphocytes (12) and serum antifilarial IgE and IgG4 levels are usually elevated $(9,13)$. In contrast, strong filarial Agdriven $T$ and $B$ cell responses are observed among amicrofilaremic individuals with chronic lymphatic obstruction (CP).

The mechanisms underlying the apparent immunological hyporeactivity in MF patients are poorly understood. Previous studies in patients with brugian filariasis have suggested active suppression by either monocytes (8) or suppressor CD8 ${ }^{+} \mathrm{T}$ lymphocytes (7). Similar studies with PBMC from persons with Wuchereria bancrofti infection have failed to identify such suppressor cell populations $(11,14)$. Furthermore, the observation that PBMC from MF patients with bancroftian filariasis did not produce parasite-specific antibody in response to either parasite $\mathrm{Ag}$ or the $\mathrm{T}$ cell-dependent $\mathrm{B}$ cell mitogen, PWM (14), suggested that MF subjects may, in fact, lack Ag-responsive $T$ cells. Indeed, we recently reported that MF subjects appear to have significantly reduced frequencies (Fo) of filarial Ag-specific $\mathrm{T}$ cells, estimated by limiting dilution analysis, compared with individuals with $\mathrm{CP}$ that approached that of normal uninfected individuals (12). However, in the limiting dilution analysis, we observed that cultures with fewer lymphocytes often had similar, and sometimes even greater, numbers of cells capable of proliferating to filarial Ags than did cultures seeded with larger numbers of $T$ cells. This observation suggested that several interacting populations of $\mathrm{Ag}$-reactive $\mathrm{CD}^{+}$cells might exist and could modulate the response of other cells to parasite antigens. In addition, these studies highlighted a limitation of standard limiting dilution analysis since lymphocyte proliferation represents a late $\mathrm{T}$ cell response that may be influenced by cross-regulatory molecules such as IL-10, TGF- $\beta$, or IFN- $\gamma(15-17)$. Furthermore, T cells may secrete

1. Abbreviations used in this paper: $\mathrm{Ag}$, antigen; $\mathrm{BmA}$, Brugia malayi filarial antigen; CP, chronic lymphatic obstruction; ELISPOT, filter spot-ELISA; Fo, frequencies; MF, microfilaremia; PPD, purified protein derivative. 
cytokines (e.g., IL-4 and IL-5) rather than proliferate strongly in response to antigens. Thus, the present study evaluated $T$ cell responses to parasite Ags by analysis of cytokine production by individual peripheral blood-derived lymphocytes in filarial infected individuals.

In the current study we therefore determined: $(a)$ whether MF subjects had lymphocytes capable of responding to parasite $\mathrm{Ag}$, as determined by cytokine secretion of individual $\mathrm{T}$ cells using a filter immunoplaque assay; $(b)$ whether different patterns of cytokine production (e.g., IFN- $\gamma$ vs. IL-4) are produced by individual lymphocytes from MF vs. CP subjects; and (c) whether the "impaired" $T$ cell proliferation characteristically seen in MF individuals results from active suppression by the production of additional cytokines such as IL-10 or TGF- $\beta$.

\section{Methods}

Study population. 29 adult volunteers living in the area of Madras, India, where bancroftian filariasis is endemic, were studied. Clinical history, physical examination, and PBMC were obtained from each study participant. Microfilariae were enumerated by filtration of $3 \mathrm{ml}$ of nocturnally collected blood through a polycarbonate filter (Nuclepore Co., Pleasanton, CA) (18). Additionally, five normal North American individuals ( three females and two males) between 30 and $41 \mathrm{yr}$ of age were studied as controls. Not all patients were studied with all of the assays. Selection was based only on the availability of patients for study.

Antigens and mitogens. Brugia malayi filarial antigen (BmA) was prepared as the saline extract of adult-stage parasites (9). PWM (GIBCO BRL, Gaithersburg, MD) and the mycobacterial Ag, purified protein derivative (PPD) (Connaught Labs, Willowdate, Ontario, Canada), were used in parallel cultures.

Isolation of PBMC. All studies were performed on fresh PBMC separated by Ficoll-diatrizoate gradient centrifugation (19) from heparinized venous blood.

ELISA for parasite-specific IgG and IgE. The ELISA for parasitespecific IgG and a solid-phase RIA for IgE were performed with BmA antigen exactly as described previously $(14,20)$.

Filter spot-ELISA (ELISPOT). ELISPOTs to determine the frequency of specific cytokine-producing lymphocytes were performed as described previously (21). For all assays, PBMC were used with the antigens (BmA or PPD) or with a combination of $50 \mathrm{ng} / \mathrm{ml}$ phorbol 12-myristate 13 -acetate (PMA) and $1 \mu \mathrm{g} / \mathrm{ml}$ ionomycin. These mitogens were used together because they produced maximal IL-4/IL-5 synthesis compared with other mitogenic stimuli tested (our personal observations).

Analysis of cytokine $m R N A$. PBMC were cultured at $3 \times 10^{6}$ cells/ $\mathrm{ml}$ in 1-ml cultures. After 12 and $48 \mathrm{~h}, \mathrm{PBMC}$ were placed directly into RNAzol B (Tel-Test, Friendswood, TX) and stored at $-70^{\circ} \mathrm{C}$ until use. RNA isolation was performed as described (22). Cytokine transcript levels were measured using a modification of a semiquantitative reverse transcriptase PCR technique previously described $(15,23)$. Briefly $1 \mu \mathrm{g}$ of total RNA was reversed transcribed using Moloney murine leukemia virus reverse transcriptase (GIBCO BRL) in a 50- $\mu$ l reaction. The reaction mixture was then diluted $1: 4$, and $10 \mu \mathrm{l}$ of diluted product was used for specific amplification of cytokine mRNA using Taq DNA polymerase (Promega Biotec, Madison, WI). PCR products were separated on a $1 \%$ agarose gel and transferred to a Hybond $\mathrm{N}^{+}$membrane (Amersham International, Amersham, UK) using standard blotting techniques. Southern transfers were subsequently probed with internal cytokine-specific oligonucleotides and visualized using the enhanced chemiluminescence detection system (Amersham International). Autoradiographs were scanned with a scanner (model 600ZS; Microtek, Torrance, CA). PCR reaction conditions were strictly defined for each cytokine such that a log-linear relationship was obtained between the amount of specific cytokine mRNA and the sig- nal density of the probed PCR product in the detection systems. The amount of cytokine-specific mRNA in a sample was determined by comparison of the signal density of the probed PCR product with that of standard curve generated by simultaneous amplification and probing of step-wise dilutions of reverse transcribed product for known amounts of mRNA. To control for the relative amount of products reverse transcribed and to assess the amount of mRNA in each sample, concurrent measurement of mRNA for the constitutively expressed gene hypoxanthine-quanine phosphoribosyl transferase (HPRT) was made. The oligonucleotide sequences for HPRT, IL-10, and TGF- $\beta$ used have been previously described (24).

Proliferation assays. PBMC $\left(10^{6} / \mathrm{ml}\right)$ were cultured in round-bottomed microtiter plates in $0.2 \mathrm{ml}$ of C-RPMI 1640 supplemented with gentamicin $(80 \mu \mathrm{g} / \mathrm{ml})$, Hepes $(25 \mathrm{mM})$, and $10 \%$ human $\mathrm{AB}$ serum. Media (control), BmA, PPD, or PWM were added to the wells. Cultures were performed in quadruplicate or sextuplicate and maintained in a humidified atmosphere with $5 \% \mathrm{CO}_{2}$ at $37^{\circ} \mathrm{C}$. After $6 \mathrm{~d}, 20 \mu \mathrm{l}$ of C-RPMI containing $1 \mu \mathrm{Ci}\left[{ }^{3} \mathrm{H}\right.$ ] thymidine (New England Nuclear, Boston, MA) was added to the cultures that were then incubated for an additional $16 \mathrm{~h}$ before the cells were collected on glass filters with a cell harvester (Skatron Inc., Sterling, VA). Thymidine incorporation was measured by liquid scintillation spectroscopy (Pharmacia LKB Nuclear Inc., Uppsala, Sweden ).

Neutralizing anticytokine antibodies. Neutralizing anticytokine antibodies (or appropriate control antibodies) were used as follows: $(a)$ anti-IL-10 (JES 3-9D7 [53]) at $10 \mu \mathrm{g} / \mathrm{ml}$ (irrelevant rat mAb of the IgG1 isotype was used as a control); $(b)$ anti-TGF- $\beta$ polyvalent chicken $\mathrm{Ab}$ and appropriate control antiserum at $5 \mu \mathrm{g} / \mathrm{ml}$ (AB-101NA; R\&D Systems, Minneapolis, MN); (c) anti-IL-2 polyvalent rabbit serum (1:200 dilution) with preimmune sera control; and $(d)$ antiIFN- $\gamma$ polyvalent rabbit serum (1:200 dilution) with preimmune sera control as previously described (25).

Data analysis. Means were compared using Student's $t$ test with logarithmically transformed data. The Fisher's exact test was used to examine the effect of anti-IL-10 and anti-TGF- $\beta$ Abs on lymphocyte proliferation shown in Fig. 1.

\section{Results}

Study subjects. Patients were selected based on their availability and classified into two groups. Asymptomatic individuals with circulating MF and patients without MF but who had a history of lymphangitis or lymphadenitis and evidence of chronic lymphatic obstruction (CP) in one or more limbs were studied. The CP patients were of both sexes and older (median age, $40 \mathrm{yr}$ ) than the MF patients (median age, $30 \mathrm{yr}$ ). Serum filaria-specific IgG4 and polyclonal IgE levels were markedly elevated in MF individuals and significantly higher than among CP subjects (Table I). In healthy uninfected North American individuals specific IgG4 is undetectable and polyclonal IgE is $<450 \mathrm{ng} / \mathrm{ml}$. In contrast, total serum IgG levels were significantly lower among MF vs. CP subjects (Table I). Filarial-specific serum IgG levels (MF, geometric mean [GM] $=442 \mathrm{U} / \mathrm{ml} ; \mathrm{CP}, \mathrm{GM}=585 \mathrm{U} / \mathrm{ml})$ and $\mathrm{IgE}$ levels $(\mathrm{MF}, \mathrm{GM}$ $=101 \mathrm{ng} / \mathrm{ml} ; \mathrm{CP}, \mathrm{GM}=120 \mathrm{ng} / \mathrm{ml}$ ) were similar between the two groups.

Lymphocyte proliferation responses to filarial Ags among MF individuals were significantly diminished compared with CP subjects (Table I; $P<0.05$ ). This Ag-specific immune "unresponsiveness" in MF individuals was restricted to filarial antigens as the mean PPD-driven $T$ cell proliferation was similar in the two groups (MF, GM stimulation index [S.I.] = 14; CP, GM S.I. $=34 ; P=0.32$ ).

Enhanced Fo of IL-4 relative to IFN- $\gamma$ secreting lymphocytes in MF vs. CP subjects. Because T cell proliferation is a late and restricted indicator of $\mathrm{T}$ cell behavior, we examined an- 
Table I. Patient Population: Clinical Characteristics and Serum Antibody Levels

\begin{tabular}{|c|c|c|c|c|c|c|}
\hline \multirow[b]{2}{*}{ Diagnosis } & \multirow{2}{*}{$\begin{array}{c}\text { Median } \\
\text { age }\end{array}$} & \multirow[b]{2}{*}{ Microfilariae } & \multirow{2}{*}{$\begin{array}{c}\text { Filarial-specific } \\
\text { IgG4 }\end{array}$} & \multicolumn{2}{|c|}{ Polyclonal } & \multirow{2}{*}{$\begin{array}{c}\text { Stimulation } \\
\text { indices to } \mathrm{BmA}\end{array}$} \\
\hline & & & & IgG & $\operatorname{lgE}$ & \\
\hline & $y r$ & $n o . / m l$ & $\mu g / m l$ & $\mathrm{mg} / \mathrm{ml}$ & $n g / m l$ & \\
\hline $\mathrm{MF}(n=12)$ & $30(21-39)$ & $414(78-960)^{*}$ & $48(13-132)^{\ddagger}$ & $1,300(940-1,540)^{\S}$ & $2,724(796-7,560)^{\S}$ & $2.2(0.8-6.6)^{\prime}$ \\
\hline $\mathrm{CP}(n=17)$ & $40(24-65)$ & 0 & $0.2(0-71)$ & $2,009(1,510-2,550)$ & $859(97-8,200)$ & $48(3.8-770)$ \\
\hline
\end{tabular}

${ }^{*}$ Geometric means (range). ${ }^{\ddagger} P<0.001$ compared with $\mathrm{CP} .{ }^{\S} P<0.01$ compared with $\mathrm{CP} . \quad " P<0.05$ compared with $\mathrm{CP}$.

other measure of immune response to specific antigens, that of cytokine production. Because of the low frequency of antigenreactive $\mathrm{T}$ cells and the ephemeral nature of IL-4 in culture supernatants, cytokine production by individual lymphocytes was examined by ELISPOT. The geometric mean Fo of cells secreting IL-4 in response to $\operatorname{BmA}(1: 11,730)$ were similar among $\mathrm{MF}$ subjects compared to $\mathrm{CP}$ individuals (GM $=1: 29,400 ; P=0.08$ ) (Fig. $1 A$ ). In contrast, BmA-driven IFN- $\gamma$-secreting lymphocytes were significantly diminished among $\mathrm{MF}$ individuals $(\mathrm{GM}=1: 39,340)$ relative to $\mathrm{CP}$ subjects $(\mathrm{GM}=1: 4,230 ; P<0.01)$ (Fig. $1 B)$. Thus, though $\mathrm{MF}$ and CP individuals showed similar Fo of IL-4-secreting cells in response to filarial antigen, the relatively low Fo of IFN- $\gamma$ secreting lymphocytes from MF compared with CP subjects indicated that the ratios of $\mathrm{Ag}$-driven IL-4 to IFN- $\gamma$-secreting lymphocytes in the PBMC were distinctly different in the two clinical groups. MF patients averaged eightfold greater Fo of IL-4- to IFN- $\gamma$-secreting cells (Fig. 1C), whereas the numbers of IFN- $\gamma$-secreting lymphocytes exceeded that of IL-4-secreting cells among most $\mathrm{CP}$ subjects.

The increased ratio of IL- 4 to IFN- $\gamma$-secreting cells was restricted to filarial antigens. The Fo of PPD-driven IFN- $\gamma$ secreting lymphocytes was equivalent for MF and CP subjects $(\mathrm{GM}=1: 5,710$; range, $1: 2,370-12,050 ;$ and $\mathrm{GM}=1: 3,944$; range, 1:917-47,170, respectively; $P=0.2$ ) and $P P D$ induced rare IL-4-secreting lymphocytes with a Fo that was also not significantly different between the two groups $(\mathrm{CP}, \mathrm{GM}=1: 9$ $\times 10^{6} ;$ and $\left.\mathrm{MF}, \mathrm{GM}=1: 3.3 \times 10^{6} ; P=0.31\right)$.
IL-10 and TGF- $\beta$ mRNA levels in $M F$ vs. CP individuals. In addition to IL-4, IL-10 has also been associated with a T helper type 2 ( $\mathrm{Th} 2$ ) pattern of cytokine production in murine models of helminth infection and correlates with downregulation of Thl responses $(16,26-28)$. Although a more ubiquitously produced cytokine than IL-10, TGF- $\beta$ also suppresses lymphocyte proliferation (17). To examine whether MF subjects produced more IL-10 and/or TGF- $\beta$ compared with $C P$ individuals, mRNA levels were measured in filarial Ag-stimulated PBMC. IL-10 mRNA transcripts were present in five of five MF subjects studied, whereas comparatively little IL-10 production occurred in CP individuals (Fig. 2). This difference was statistically significant based on a comparison of the ratio of IL-10 to HPRT density units, (CP, mean $=0.11 \pm .01$ vs. $\mathrm{MF}$, mean $=0.57 \pm 0.31 ; P<0.01)$. Ag-induced TGF- $\beta$ mRNA was present in four of five MF individuals and in two of the four CP individuals examined (data not shown).

$I L-10$ and TGF- $\beta$ suppress Ag-driven $T$ cell proliferation responses in $M F$ and not $C P$ subjects. Since IL-10 production was preferentially elevated among MF subjects compared with $\mathrm{CP}$ individuals and a principal action of this cytokine is to inhibit antigen-driven lymphocyte proliferation (27-29), the role of IL-10 in mediating the Ag-specific "defect" in proliferative response seen in MF was examined in the presence of neutralizing $\mathrm{Ab}$ to IL-10. Anti-IL-10 significantly augmented by $220-1,300 \% \mathrm{BmA}$-driven $\mathrm{T}$ cell proliferation in 7 of $10 \mathrm{MF}$ patients, whereas it had no effect on $\mathrm{T}$ cell proliferation in the $11 \mathrm{CP}$ subjects studied ( $P<0.01$; Fig. 3 , left $)$. Note the overall

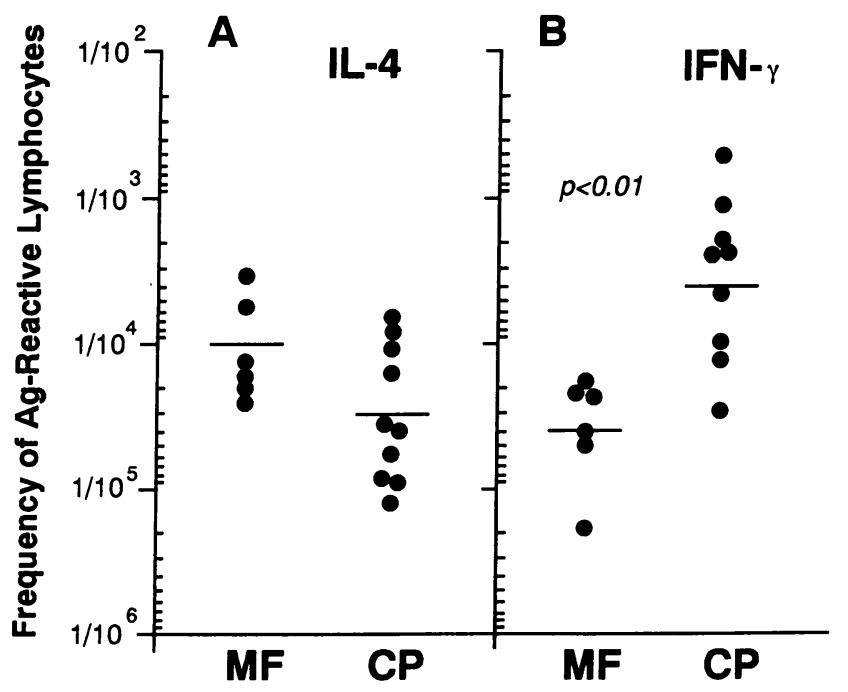

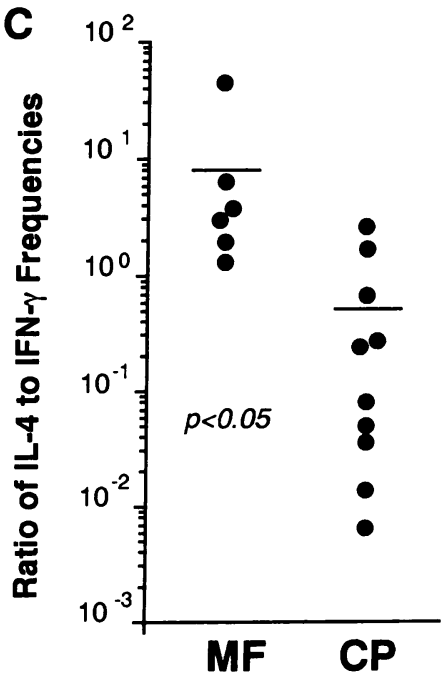

Figure 1. Frequency of Ag-reactive lymphocytes in PBMC secreting IL-4 $(A)$ or IFN- $\gamma(B)$, or the ratio of the frequencies (C) from patients with CP and MF. Each point represents one individual and the horizontal lines indicate the geometric means. 

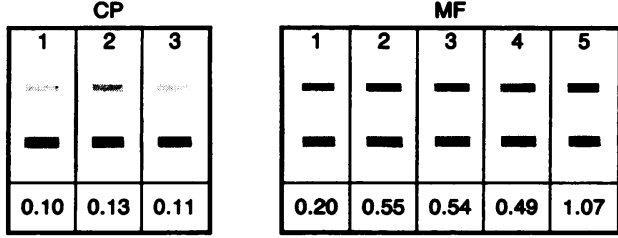

IL-10

HPRT

IL-10/HPRT Ratio

Figure 2. Levels of IL-10 and HPRT mRNA in parasite antigendriven PBMC from individuals with CP or MF. The ratio of denistometric units for IL-10 and HPRT mRNA is shown below each individuals' autoradiographs.

diminished $\mathrm{T}$ cell proliferative response in MF (vis-a-vis $\mathrm{CP}$ subjects) as evidenced by the different scales on the $y$-axis in Fig. 3. Although $\mathrm{T}$ cell proliferation was augmented in most MF subjects in the presence of neutralizing IL-10 antibody, even the enhanced proliferation among MF subjects generally remained below that of the $\mathrm{CP}$ patients.

TGF- $\beta$ mRNA levels were also elevated in two MF subjects and may also contribute to the modulation of lymphocyte proliferation responses (17). In parallel experiments, neutralizing anti-TGF- $\beta$ Ab added to cell cultures also significantly augmented, although to a lesser degree, Ag-driven $\mathrm{T}$ cell proliferation in PBMC from 5 of 10 individuals with MF, but caused no enhanced response by $\mathrm{T}$ cells of $\mathrm{CP}$ individuals $(P<0.05)$ (Fig. 1).

The effect of neutralizing anti-IL- 2 and anti-IFN- $\gamma$ antibodies on $\mathrm{T}$ cell proliferation in both groups was studied in parallel to that of anti-IL-10 and anti-TGF- $\beta$. Neutralizing anti-IL-2 Abs significantly inhibited Ag-driven $\mathrm{T}$ cell proliferation in 3 of $10 \mathrm{MF}$ and 8 of $11 \mathrm{CP}$ subjects. Neutralizing anti-IFN- $\gamma \mathrm{Ab}$ had no consistent effect on $\mathrm{T}$ lymphocyte proliferation in either group (data not shown).

\section{Discussion}

Impaired lymphocyte proliferation responses to filarial antigens have been consistently observed in individuals with circulating MF compared with amicrofilaremic subjects $(4,5,11$, 12). The recent understanding that lymphocytes produce a broad array of cytokines that may influence the pattern of host responses suggested further study of cytokine production in filarial infections. The present study demonstrates that MF individuals possess filarial Ag-reactive lymphocytes that respond fully to filarial antigens; their response, however, was primarily in IL-4 production (and not IFN- $\gamma$ secretion). This contrasted with the more immunologically responsive $\mathrm{CP}$ individuals, who had a greater number of $\mathrm{Ag}$-driven IFN- $\gamma$-secreting cells

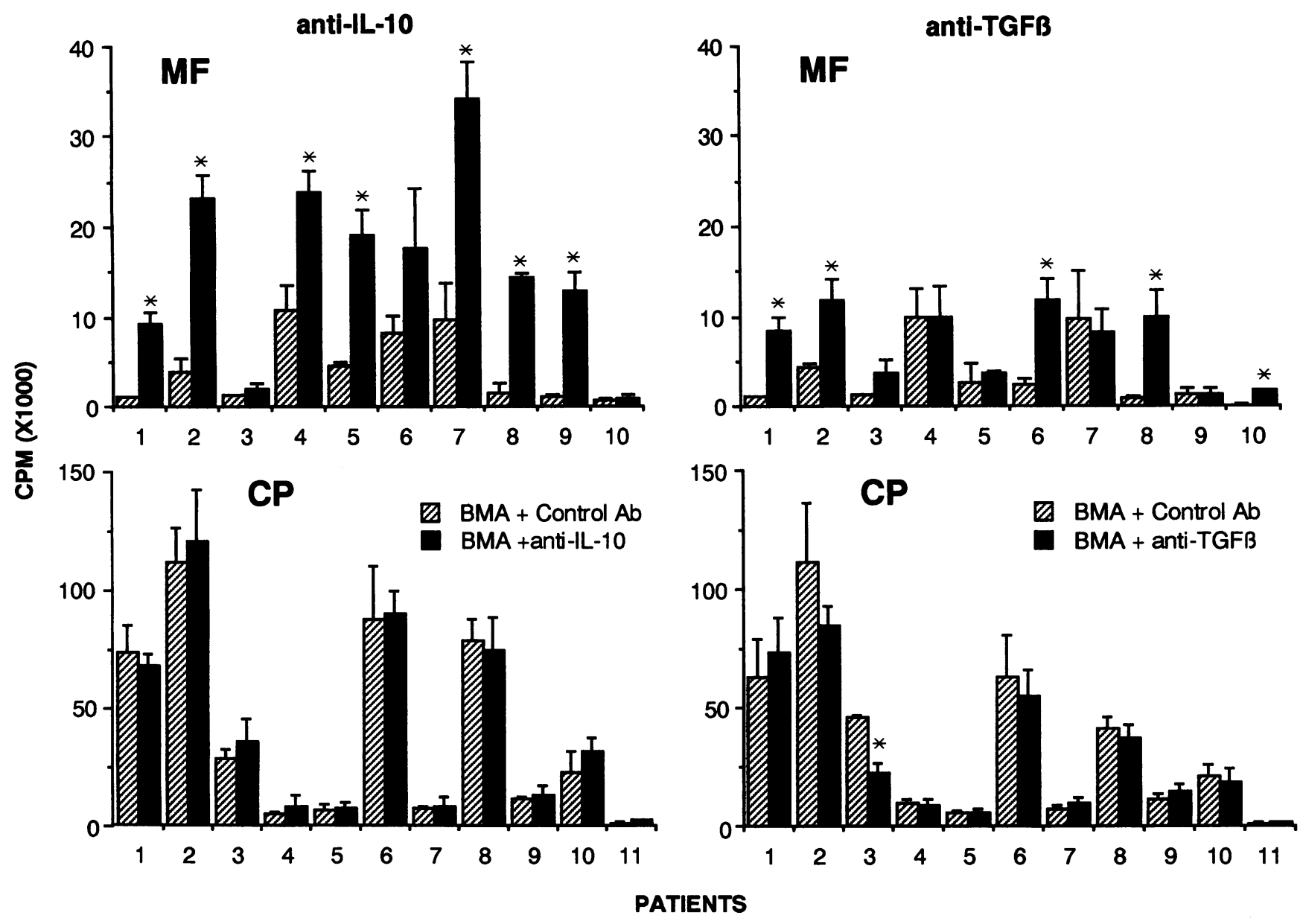

Figure 3. Effect of neutralizing anti-IL-10 and anti-TGF- $\beta$ Abs on parasite Ag-driven T cell proliferation. Each paired set of bars represents an individual's mean $( \pm \mathrm{SD})$ net parasite $\mathrm{Ag}$-driven proliferation $(\mathrm{cpm})$ of triplicate cultures in the presence of the appropriate control Abs or with anti-IL-10 Ab (left) or anti-TGF- $\beta \mathrm{Ab}$ (right). Asterisks represent values that are significantly different from controls $(P<0.05)$. 
relative to IL-4. This pattern of cytokine production was restricted to filarial antigens as the Fo of IL-4- and IFN- $\gamma$ secreting cells to the nonparasite $\mathrm{Ag}$, PPD, were equivalent between the two groups. The predominant IL-4 response to filarial Ags and elevated serum levels of polyclonal $\mathrm{IgE}$ and filarial-specific IgG4 suggests a Th2-like pattern of cytokine production. In contrast, the increased numbers of filarial Agspecific IFN- $\gamma$-secreting cells, strong lymphocyte proliferation responses, and previous observations of enhanced IL-2 production (relative to MF subjects in response to filarial Ags [14]) demonstrated a Th1-like pattern of cytokine synthesis among symptomatic, amicrofilaremic individuals (CP). Thus, the impaired lymphocyte proliferation among MF subjects results not from a lack of Ag-reactive lymphocytes, but from a pattern of $\mathrm{T}$ cell activation that generates cytokines (increased IL-4 and diminished IFN- $\gamma$ ), which promotes humoral responses and not lymphocyte proliferation.

Although less potent than IL-2, IL-4 also induces T cell proliferation ( 30 ), and the almost complete absence of $T$ cell blastogenesis in some MF subjects observed in the present and previous studies $(4,5,11)$ suggested downmodulation of the Thl response. To address this question two cytokines that suppress lymphocyte proliferation were examined: IL-10 and TGF- $\beta$ (17, 27-29). Ag-driven IL-10 mRNA levels were clearly elevated in MF compared with $\mathrm{CP}$ individuals. Although Ag-induced TGF- $\beta$ mRNA levels were elevated in $80 \%$ of MF vs. $50 \%$ of CP subjects, the number of individuals studied was too small to draw any conclusions about significant differences between the two groups. More importantly, neutralizing Abs to IL- 10 and TGF- $\beta$ significantly enhanced Ag-specific lymphocyte proliferation among MF and not $\mathrm{CP}$ subjects, indicating that these cytokines contribute to a component of active downmodulation. Whether IL-4 also contributes to this cross-regulation is currently being investigated.

The principal subpopulation of PBMC responsible for increased IL-10 production by MF subjects remains to be defined, however, recent studies in normal human PBMC suggest monocytes are a major source of IL-10 (27). Indeed, monocyte ( or B cell)-derived IL-10 could account for the findings in a previous study in brugian filariasis demonstrating that depletion of adherent cells from PBMC can partially reverse the impaired $\mathrm{T}$ cell proliferation in MF subjects (8). The mechanism of this IL-10 suppression of lymphocyte proliferation likely occurs by inhibiting APC expression of MHC II (28) or certain molecules such as $\mathrm{B} 7 / \mathrm{BB} 1$ necessary for $\mathrm{T}$ cell activation (31).

Recently, in a study of a clinically similar group of MF subjects ( $\mathrm{S}$. Mahanty, unpublished observations), neutralizing $\mathrm{Ab}$ to IL-10 failed to augment Ag-specific IL-4 or IFN- $\gamma$ production, although in this set of patients lymphocyte proliferation to parasite $\mathrm{Ag}$ tended to be roughly twofold greater than that observed in the present study. Clearly, the precise role that IL-10 plays in suppressing lymphocyte responses in MF subjects remains to be fully defined. Nevertheless, modulation of lymphocyte responses in patients with MF are likely to be multifactorial with a predominant $\mathrm{Th} 2$ response to filarial Ags contributing the major component. Active downmodulation by cross-regulatory cytokines such as IL-10 and TGF- $\beta$ may contribute both to an Ag-specific component ( $\mathrm{T}$ cell-derived IL10) and an Ag-nonspecific component (APC-derived IL-10 and TGF- $\beta$ ).
The relative expression of filarial antigen-driven IFN- $\gamma$ and IL-4 secretion by individual lymphocytes appears to mirror the clinical spectrum of response in lymphatic filariasis. The downregulation of IFN- $\gamma$ production and lymphocyte proliferation in MF subjects may diminish induction of cellular effectors that contribute to the pathology of the disease and facilitate removal of the microfilariae. In addition, enhanced IL-4 synthesis generates strong humoral responses, particularly polyclonal IgE, that may facilitate persistence of infection through the production of irrelevant ( not parasite Ag-specific) IgE that saturates high affinity IgE receptors expressed on mast cells and renders them unable to be specifically cross-linked by parasite antigen.

The presence of strong Th2 responses to helminth infections has been well established in murine models of Schistosoma mansoni (32), Nippostrongylus brasilensis (33), Heligmosomoides polygyrus (34), and Strongyloides venezuelensis (35). The relative balance of cytokines associated with Th1 and Th2 subsets of $\mathrm{CD}^{+}{ }^{+}$cells may determine the outcome of the host response to infections with Leishmania (36), Trichinella (37), Schistosome (38), and Nippostrongylus species (33). In murine models of schistosomiasis, the induction of a Th2 response with egg deposition and associated suppression of a Th 1 response correlated with increased IL- 10 production (26). Similar to observations in the present study, addition of neutralizing anti-IL-10 Ab to antigen-driven lymphocyte cultures from schistosome-infected or (26) filarial-infected mice (39) enhanced T cell proliferation and Thl cytokine production. These studies suggest an analogous immunomodulatory role of IL-10 in murine models of helminth infections.

Profiles of cytokine responses in relation to the spectrum of disease have also been examined in human schistosomiasis. Humans with chronic schistosome infections are often asymptomatic, have diminished granuloma size (40), and manifest depressed antigen-specific $T$ cell proliferation, IFN- $\gamma$ production, and IL-2 production along with augmented mitogen-driven IL-4 synthesis in culture supernatants of PBMC $(41,42)$. After specific chemotherapy for schistosomiasis, parasite Agdriven $T$ cell proliferation (43), along with IFN- $\gamma$ and IL-2 production by PBMC, increases significantly (41), thereby indicating a depressed Th1-like response during chronic infections.

The preferential induction of IL- 4 relative to IFN- $\gamma$ production (Th2-like response) in MF subjects may result from in utero ( or perinatal ) exposure to parasite antigens or to antiidiotype antibodies that render lymphocytes "unresponsive" to parasite antigens (as determined by lymphocyte proliferation). Indirect evidence for prenatal sensitization has come from findings that antifilarial antibodies of isotypes that do not cross the placenta (e.g., IgE and IgM) can be identified in the cord blood of babies born to infected mothers (44) or in the cord sera of babies born in a region endemic for $W$. bancrofti (45). This neonatally induced tolerance may be restricted to the Th 1 subset whereas Th2 responses may escape the induction of tolerance, a possibility supported by recent studies in which alloantigens given to neonatal mice resulted in donor-specific expansion of Th2 cells $(46,47)$. Thus, lymphocytes obtained from infant cord blood or young children born from microfilaremic mothers may preferentially produce IL-4 compared with IFN$\gamma$ or IL- 2 in response to parasite antigen stimulation, in contrast to the offspring of amicrofilaremic mothers. 
Alternatively, the preferential induction of a Th2-like response in MF subjects may result from peripheral tolerance. This concept implies that a state of proliferative unresponsiveness is caused by an absence of a costimulatory signals from the APC. Therefore, acquisition of infection in childhood may allow establishment the microfilaremic state, which, in turn, leads to a high intravascular antigen load that saturates resting B cells (or other APC [48]) or fails to induce costimulatory ligands that could then lead to the preferential induction of Th2 responses (49).

In the present study, we have demonstrated that MF subjects respond to filarial Ags and produce cytokines (e.g., IL-4, IL-10, and TGF- $\beta$ ) that have an antiinflammatory effect. Furthermore, these data suggest that cytokine cross-regulation can contribute to the impaired $\mathrm{T}$ cell proliferation observed among MF subjects and may be diminished further by a relative decrease in the Fo IFN- $\gamma$-secreting lymphocytes (and by inference IL-2-secreting cells) compared with IL-4-producing cells. Most importantly, these data indicate that our definition of tolerance should not be limited to the absence of Ag-reactive proliferation of $\mathrm{T}$ cells but should be broadened to include the notion that states of "specific immune unresponsiveness" may be a reflection of an altered balance of immune reactivity.

\section{Acknowledgments}

We thank A. Maya, S. Usha, and S. Kumari for their technical assistance throughout all aspects of this project. In addition, we thank Pat Amato for help in preparation of the manuscript and Dr. James Kazura for his thoughtful discussions and critical review of the paper.

The DNAX Research Institute is entirely supported by the Schering-Plough Corporation.

\section{References}

1. WHO Expert Committee on Filariasis. 1984. Lymphatic filariasis. WHO Tech. Report No. 702. Geneva, Switzerland. 7-107.

2. Ottesen, E. A. 1980. Immunopathology of lymphatic filariasis in man. Springer Semin. Immunopathol. 2:373-385.

3. Ottesen, E. A., P. F. Weller, M. Lunde, and R. Hussain. 1982. Endemic filariasis on a Pacific Island. II. Immunological aspects: Immunoglobulin, complement, and specific antifilarial IgG, IgM and IgE antibodies. Am. J. Trop. Med. Hyg. 31:953-961.

4. Ottesen, E. A., P. F. Weller, and L. Heck. 1977. Specific cellular immune unresponsiveness in human filariasis. Immunology. 33:413-421.

5. Piessens, W. F., P. B. McGreevy, P. W. Piessens, M. McGreevy, J. Koiman, H. S. Sarsoso, and D. T. Dennis. 1980. Immune responses in human infections with Brugia malayi. Specific cellular unresponsiveness to filarial antigens. J. Clin. Invest. 65:172-179.

6. Weller, P. F., E. A. Ottesen, and L. Heck. 1980. Immediate and delayed hypersensitivity skin test responses to the Dirofilaria immitis filarial skin test (Sawada) antigen in Wuchereria bancrofti filariasis. Am. J. Trop. Med. Hyg. 29:809-814.

7. Piessens, W. F., F. Partono, S. L. Hoffman, S. Tatiwayanto, P. W. Piessens, J. R. Palmieri, J. Koiman, D. T. Dennis, and W. P. Carney. 1982. Antigen-specific suppressor T lymphocytes in human lymphatic filariasis. N. Engl. J. Med. 307:144-148.

8. Piessens, W. F., S. Ratiwaytano, S. Tuti, J. H. Palmeiri, P. W. Pieseens, J. Koiman, and D. T. Dennis. 1980. Antigen-specific suppressor cells and suppressor factors in human filariasis with Brugia malayi. N. Engl. J. Med. 302:833-837.

9. Hussain, R., R. G. Hamilton, V. Kumaraswami, N. F. Adkinson, and E. A. Ottesen. 1981. IgE response in human filariasis. I. Quantitation of filaria-specific IgE. J. Immunol. 127:1623-1629.

10. McGreevy, P. B., S. Ratiwayanto, S. Tuti, M. M. McGreevy, and D. T. Dennis. 1980. Brugia malayi: Relationship between anti-sheath antibodies and amicrofilaremia in natives living in an endemic area of South Kalmantan, Borneo. Am. J. Trop. Med. Hyg. 29:553-562.

11. Nutman, T. B., V. Kumaraswami, and E. A. Ottesen. 1987. Parasite-speci- fic anergy in human filariasis. Insights after analysis of parasite antigen-driven lymphokine production. J. Clin. Invest. 79:1516-1523.

12. King, C. L., V. Kumaraswami, R. W. Poindexter, S. Kumari, K. Jayaraman, D. W. Alling, E. A. Ottesen, and T. B. Nutman. 1992. Immunologic tolerance in lymphatic filariasis: diminished parasite-specific $T$ and $B$ lymphocyte precursor frequency in the microfilaremic state. J. Clin. Invest. 89:1403-1410.

13. Ottesen, E. A., F. Skvaril, S. P. Tripathy, R. W. Poindexter, and R. Hussain. 1985. Prominence of IgG4 in the IgG antibody response to human filariasis. J. Immunol. 134:2707-2712.

14. Nutman, T. B., V. Kumaraswami, L. Pao, P. R. Narayanan, and E. A. Ottesen. 1987. An analysis of in vitro B cell immune responsiveness in human lymphatic filariasis. J. Immunol. 138:3954-3959.

15. Oswald, I. P., T. A. Wynn, A. Sher, and S. L. James. 1992. Interleukin 10 inhibits macrophage microbicidal activity by blocking the endogenous production of tumor necrosis factor alpha required as a costimulatory factor for interferon gamma-induced activation. Proc. Natl. Acad. Sci. USA. 89:8676-8680.

16. Mosmann, T. R., and K. W. Moore. 1991. The role of IL-10 in crossregulation of Th1 and Th2 responses. Immunol. Today. 12:A49-53.23.

17. Sporn, M. B., and A. B. Roberts. 1990 . The transforming growth factor- $\beta$ s. In Peptide Growth Factors and Their Receptors I. M. B. Sporn and A. B. Roberts, editors. Springer Publishing Company, New York. 419-432.

18. Weller, P. F., and E. A. Ottesen. 1978. Failure of diethylcarbamazine as a provocative test in subperiodic Wunchereria bancrofti filariasis. Trans. $R$. Soc. Trop. Med. Hyg. 7:31-32.

19. Boyum, A. 1968. Separation of leukocytes from blood and bone marrow. Scan. J. Clin. Lab. Invest. 21 (Suppl. 97):77-89.

20. Hamilton, R. G., R. Hussain, E. A. Ottesen, and J. N. F. Adkinson. 1981. The quantitation of parasite-specific human IgG and IgE in sera: evaluation of solid-phase RIA and ELISA methodology. J. Immunol. Methods. 44:101-114.

21. Mahanty, S., J. S. Abrams, C. L. King, A. P. Limaye, and T. B. Nutman. 1992. Parallel regulation of IL-4 and IL-5 in human helminth infections. J. Immunol. 148:3567-3571.

22. Chomczynski, P., and N. Sacchi. 1987. Single-step method of RNA isolation by acid quanidinium thiocyanate-phenol-chloroform extraction. Anal. Biochem. 162:156-159.

23. Svetic, A., F. D. F. D. Finkelman, Y. C. Jian, C. W. Dieffenbach, D. E. Scott, K. F. McCarthy, A. D. Steinberg, and W. C. Gause. 1991. Cytokine gene expression after in vivo primary immunization with goat antibody to mouse IgD antibody. J. Immunol. 147:2391-2397.

24. Karp, C. L., S. H. El-Safi, T. A. Wynn, M. M. H. Satti, A. M. Kordofani, F. A. Hashim, M. Hag-Ali, F. A. Neva, T. B. Nutman, and D. L. Sacks. 1993. In vivo cytokine profiles in patients with kala-azar. Marked elevation of both IL-10 and interferon- $\gamma$. J. Clin. Invest. 91:1644-1648.

25. King, C. L., E. A. Ottesen, and T. B. Nutman. 1990. Cytokine regulation of antigen-driven immunoglobulin production in filarial parasite infections in humans. J. Clin. Invest. 85:1810-1815.

26. Sher, A., D. Fiorentino, P. Casper, E. Pearce, and T. Mosmann. 1991. Production of IL-10 by CD4 ${ }^{+} \mathrm{T}$ lymphocytes correlates with down-regulation of Thl cytokine synthesis in helminth infection. J. Immunol. 147:2713.

27. de Waal Malefyt, R. J. Abrams, B. Bennett, C. B. Figdor, and J. E. de Vries. 1991. Interleukin 10 (IL-10) inhibits cytokine synthesis by human monocytes: an autoregulatory role of IL-10 produced by monocytes. J. Exp. Med. 174:1209-1220.

28. de Waal Malefyt, R., J. Haanen, H. Spits, M-G. Roncarolo, A. Velde, C. Figdor, K. Johnson, R. Kastelein, H. Yssel, and J. E. de Vries. 1991. Interleukin 10 (IL-10) and viral IL-10 strongly reduce antigen-specific human T cell proliferation by diminishing the antigen-presenting capacity of monocytes via downregulation of class II major histocompatibility complex expression. J. Exp. Med. 174:915-924.

29. Fiorentino D. F., A. Zlotnik, P. Vieira, T. R. Mosmann, M. Howard, K. W. Moore, and A. O'Garra. 1991. IL-10 acts on the antigen-presenting cell to inhibit cytokine production by Thl cells. J. Immunol. 146:3444-3451.

30. Tan, P., C. Anasetti, J. A. Hansen, J. Melrose, M. Brunvand, J. Bradshaw, J. A. Ledbetter, and P. S. Linsley. 1993. Induction of alloantigen-specific hyporesponsiveness in human $T$ lymphocytes by blocking interaction of CD28 with its natural ligand B7/BB1. J. Exp. Med. 177:165-173.

31. Ding, L., and E. M. Shevach. 1992. IL-10 inhibits mitogen-induced T cell proliferation by selectively inhibiting macrophage costimulatory function. $\mathrm{J}$. Immunol. 148:3133-3139.

32. Sher, A., R. L. Coffman, S. Hieny, and A. W. Cheever. 1990. Ablation of eosinophil and IgE responses with anti-IL-5 or anti-IL-4 antibody fails to affect immunity against Schistosoma mansoni in the mouse. J. Immunol. 145:39113916.

33. Finkelman, F. D., E. J. Pearce, J. J. Urban, and A. Sher. 1991. Regulation and biological function of helminth-induced cytokine responses. Immunol. Today. 12:A62-A66.

34. Urban, J. J., I. M. Katona, W. M. Paul, and R. D. Finkelman. 1991. Interleukin 4 is important in protective immunity to a gastrointestinal nematode infection in mice. Proc. Natl. Acad. Sci. USA. 88:5513-5517.

35. Korenaga, M., Y. Hitoshi, N. Yamaguchi, Y. Sato, K. Takatsu, and I. 
Tada. 1991. The role of interleukin-5 in protective immunity to Strongyloides venezuelensis infection in mice. Immunology. 72:502-507.

36. Heinzel, F. P., M. D. Sadick, B. J. Holaday, R. L. Coffman, and R. M. Locksley. 1989. Reciprocal expression of interferon gamma or interleukin 4 during the resolution or progression of murine leishmaniasis. Evidence for expansion of distinct helper T cell subsets. J. Exp. Med. 169:59-72.

37. Pond, L., D. L. Wassom, and C. E. Hayes. 1989. Evidence for differential induction of helper $\mathrm{T}$ cell subsets during Trichinella spiralis infection. J. Immunol. 143:4232-4237.

38. Pearce, E. J., P. Caspar, J. M. Grzych, F. A. Lewis, and A. Sher. 1991. Downregulation of Th1 cytokine production accompanies induction of Th2 responses by a parasitic helminth, Schistosoma mansoni. J. Exp. Med. 173:159166.

39. Pearlman, E., F. E. Hazlett Jr., W. H. Boom and J. W. Kazura. 1993. Induction of murine T-helper cell responses to the filarial nematode Brugia malayi. Infect. Immun. 61:1105-1112.

40. Domingo E. O., and K. S. Warren. 1968. Endogenous desensitization: changing host granulomatous response to schistosome eggs at different stages of infection with Schistosoma mansoni. Am. J. Pathol. 52:369-377.

41. Zwingenberger, K., E. Irschick, J. G. Siqueira Vergetti, A. R. Correia Decal, R. Janssen-Rosseck, U. Bienzle, C. Huber, and H. Feldmeier. 1989. Release of interleukin 2 and gamma interferon by peripheral mononuclear cells in human Schistosomiasis mansoni infection normalizes after chemotherapy. Scand. J. Immunol. 30:463-471.

42. Zwingenberger, K., A. Hohmann, M. Cardoso de Brito, and M. Ritter. 1991. Impaired balance of interleukin- 4 and interferon- $\gamma$ production in infec- tions with Schistosomiasis mansoni and intestinal nematodes. Scand. J. Im munol. 34:243-251.

43. Colley, D. G., I. S. Barsoum, H. S. S. Dahawi, F. Gamil, M. Habib, and M. A. El Alamy. 1986. Immune responses and immunoregulation in relation to human schistosomiasis in Egypt. III. Immunity and longitudinal studies of in vitro responsiveness after treatment. Trans. R. Soc. Trop. Med. Hyg. 80:952-957.

44. Weil, G. J., R. Hussain, V. Kumaraswami, S. P. Tripathy, K. S. Phillips, and E. A. Ottesen. 1983. Prenatal allergic sensitization to helminth antigens in offspring of parasite-infected mothers. J. Clin. Invest. 71:1124-1129.

45. Sanjeevi, C. B., and P. R. Narayanan. 1989. Antifilarial and anti-PPD IgM antibodies in cord blood. Indian J. Pediatr. 56:207-211.

46. Merino. J., S. Schurmans, M. A. Duchosal, S. Izui, and P. H. Lambert 1989. Autoimmune syndrome after induction of neonatal tolerance to alloantigens. $\mathrm{CD}^{+} \mathrm{T}$ cells from the tolerant host activate autoreactive F1 B cells. $J$. Immunol. 143:2202-2208.

47. Goldman, M., P. Druet, and E. Gleichmann. 1991. Th2 cells in systemic autoimmunity: insights from allogeneic desease and chemically-induced autoimmunity. Immunol. Today. 12:223-228.

48. Eynon, E. E., and D. C. Parker. 1992. Small B cells as antigen-presenting cells in the induction of tolerance to soluble protein antigens. J. Exp. Med. 175:131-138.

49. Chang, T.. C. M. Sea. S. Urioste, R. C. Thompson, W. H. Boom, and A. K Abbas. 1990. Heterogeneity of helper/inducer T lymphocytes III. Responses IL-2 and IL-4-producting (Th1 and Th2) clones to antigens presented by different accessory cells. J. Immunol. 145:2803-2808. 